\title{
Air Gun Pressure Influence on the Projectile Penetration of a 2Mm Mild Steel Plate
}

\author{
Faruk Razic, Zahida Ademovic, Jasmin Terzic, \\ Sabina Serdarevic-Kadic \& Miralem Burek
}
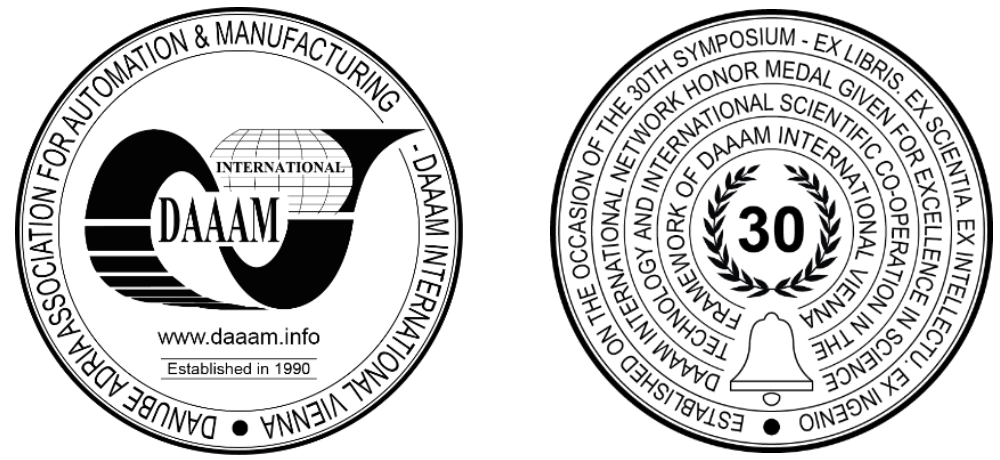

This Publication has to be referred as: Razic, F[aruk]; Ademovic, Z[ahida]; Terzic, J[asmin]; Serdarevic-Kadic, S[abina] \& Burek, M[iralem] (2021). Air Gun Pressure Influence on the Projectile Penetration of a 2mm Mild Steel Plate, Proceedings of the 32nd DAAAM International Symposium, pp.0185-0190, B. Katalinic (Ed.), Published by DAAAM International, ISBN 978-3-902734-33-4, ISSN 1726-9679, Vienna, Austria DOI: $10.2507 / 32$ nd.daaam.proceedings.028

\begin{abstract}
Guns that operate on compressed air (Air Guns) are widely used in entertainment business. They are very common in Paintball and Airsoft competitive team sports and in performance riffles. Projectiles fired from these types of guns can reach more than $400 \mathrm{~m} / \mathrm{s}$. A Projectile weighing $5 \mathrm{~g}$ at this velocity has a kinetic energy of $400 \mathrm{~J}$ upon impact. This energy is sufficient for skin penetration and infliction of serious life threating injuries. This paper deals with projectile velocities, achieved with compressed air, needed for full penetration of the mild steel plate of $2 \mathrm{~mm}$ thickness. Projectile firing has been performed with custom made Air Gun capable of reaching compressed air levels up to 10 MPa and projectile velocities up to $160 \mathrm{~m} / \mathrm{s}$. Velocity of the fired projectiles has been recorded with High Speed camera after which it was possible to determine kinetic energy upon the impact and energy density as well. Experiments presented in this paper show that compressed air operated guns can deliver significant kinetic energy to the target, capable of inflicting serious injuries
\end{abstract}

Keywords: Velocity; Air Gun; Pressure; Energy; Target.

\section{Introduction}

Paintball and Airsoft guns, more often called Markers, and performance rifles are capable of firing projectiles at very high velocities. Playground facilities for Paintball and Airsoft have limited levels of projectile velocities, $91 \mathrm{~m} / \mathrm{s}$ for Paintball and $150 \mathrm{~m} / \mathrm{s}$ for Airsoft markers [1] [2]. Performance riffles on the other hand are capable for even higher projectile velocities, more than $400 \mathrm{~m} / \mathrm{s}$. One of the fastest pellet gun on the market today is probably a Magnum Riffle by Gamo which can reach $470 \mathrm{~m} / \mathrm{s}$ (1542 fps) with $4.5 \mathrm{~mm}$ pellet [3].

Kinetic energy levels at the muzzle of a Paintball markers are quite low, around $12 \mathrm{~J}$ [4]. This energy level is achieved with $17.3 \mathrm{~mm}$ ball whose mass is $3 \mathrm{~g}$, flying at $91 \mathrm{~m} / \mathrm{s}$ velocity. Airsoft balls are quite lower in mass compared to paintball balls. At $0.4 \mathrm{~g}$ and $150 \mathrm{~m} / \mathrm{s}$ they achieve only $4.5 \mathrm{~J}$ of kinetic energy at the muzzle. On the other hand, performance rifles can achieve 5-10 times higher kinetic energy because of the much higher projectile velocity. Also, these types of Air Guns are capable of penetration of a human skin which is not the case for previous mentioned markers. 
Skin penetration can be observed as a first step in prediction of possible injury of a human body. Energy levels and energy densities at which it is possible to penetrate human skin are usually investigated using porcine body parts. Human cadavers on the other hand are rarely used for this kind of experiments and use of human cadavers is often considered unethical. In this work, penetration of a $2 \mathrm{~mm}$ thick mild steel plate was tested. Unquestionably steel plate is more resilient than human skin. Eventual penetration of a steel plate using compressed air for projectile propelling will provide visual confirmation of air gun penetration possibilities and its potential. When velocity and mass of the fired projectiles were taken into account it is possible to calculate kinetic energy and energy density at which penetration occurs.

Above mentioned kinetic energy levels are calculated for the projectile muzzle velocity. It is expected that these energy levels decrease with the shooting distance since projectile is losing velocity on its trajectory to the target. This leads to the linear decrease in wounding potential with increased distance to the target [5]. There are also other weapons used in entertainment for firing projectiles, like slingshots or blowpipes. However, energy levels achieved with these types of weapons are not sufficient for skin penetration nor they can cause serious injuries to the muscles, bones or skin [6].

Main goal of this paper is to provide data about kinetic energy and energy density at which it is possible to provide full penetration of the steel target using compressed air. There are many different reports and papers that are describing wounds gained from Air Guns. Some of those injuries turn out to be fatal for the person being hit [7]. However, data about full potential and capability of such type of guns are rather scarce.

All Air Guns are capable of firing projectiles at even higher velocities than the ones designated on the playground. This is achieved by pressure increasing in the gun tank. To which levels this pressure can be increased depends on the gun/marker properties. With increased projectile velocity, the kinetic energy and energy density will also increase. In that case there is a higher possibility for a serious injury of a human body.

As it was already stated, mass of the projectiles used in paintball and airsoft markers are quite low. Considering their low mass, velocity of the projectiles should be increased significantly to provide desired penetration energy levels. Performance rifles on the other hand are capable of delivering very high pellet velocities. However, mass of the pellet is also very low which decreases penetration abilities. Custom made Air Gun was designed for this study. This Air Gun was capable of firing heavy steel projectiles at high velocities.

\section{Case study}

Penetration capability of a compressed air driven projectiles has been examined through experiment. Custom made Air Gun, Fig. 1. has been assembled in order to provide higher levels of compression, up to $10 \mathrm{MPa}$ (1450 Psi). Achieved air pressure level was monitored with high accuracy manometer connected to the Air Gun tank. Air Guns are in general of simple construction. Main parts of an Air Gun are: Tank, Valves and Barrel. By assembling these three components one can custom made an Air Gun and use it to fire projectiles. Hence, it is not important what kind of device operated on compressed air will be used for firing. Main goal is to provide sufficient velocity for the projectile which will as a result produce desired level of kinetic energy upon impact.

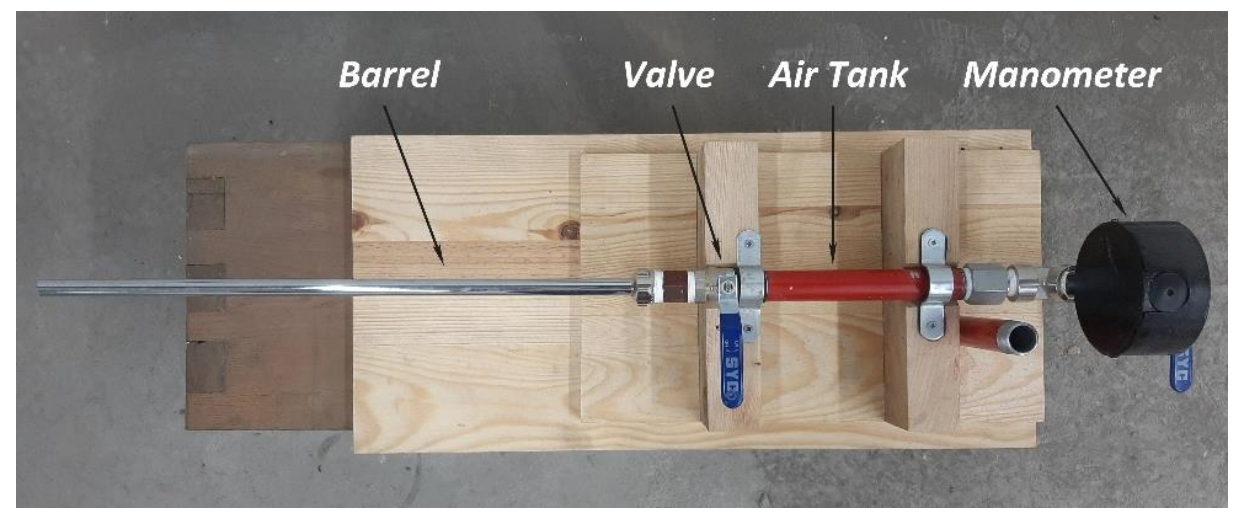

Fig. 1. Custom made Air Gun

Projectiles used in this test were $5.5 \mathrm{~mm}$ mild steel projectiles machined in to a shape that will provide high sectional density (mass to projected surface area ratio). These projectiles were fired at different pressure levels into a steel plate of $2 \mathrm{~mm}$ thickness, Fig. 2. Dimensions of the plate were $500 \times 500 \mathrm{~mm}$. Penetration of this target visually presented capabilities of impact energy provided with compressed air.

Three shooting series are performed at three different air pressure levels. Velocity was measured for each projectile fired, and with known mass of the projectile, kinetic energy and energy density are determined. In the third shooting series, piezo electric pressure sensor was installed. This sensor was capable of measuring pressure inside the Air Gun barrel. Using proper data acquisition system, pressure vs time curve was obtained. This curve describes the pressure vs time integral where it can be seen how the maximum pressure was achieved. Pressure loss was also evident. 

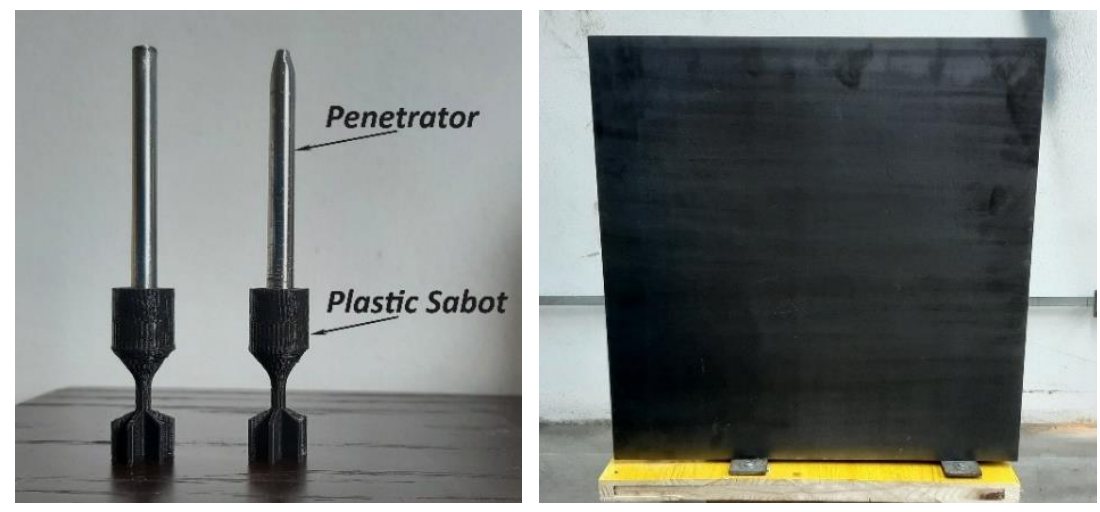

Fig. 2. Blunt and Sharp tip projectiles (left), $2 \mathrm{~mm}$ steel plate target (right)

Two different types of projectiles are used in penetration test. One with blunt and the other with sharp tip. Pressure levels at which projectiles were fired at the target, placed $500 \mathrm{~mm}$ in front of the muzzle, were 2, 3 and $5 \mathrm{MPa}$ providing velocities from 80 to $160 \mathrm{~m} / \mathrm{s}$. In order to provide flight stability and gas sealing during projectile motion through the gun barrel, plastic sabot with fins was designed. Mass of the steel penetrator without sabot was ranging from $10.00-10.86 \mathrm{~g}$. When sabot was added to the steel penetrator it formed a projectile of total mass around $12 \mathrm{~g}$.

Both, sharp and blunt projectiles are fired five times into the target at three different pressure levels and at different velocities. Deformation of the steel plate was observed and analysed after the impact. Four possible penetration outcomes are observed: Full penetration "fp" (projectile went through the target), Partial penetration "pp" (projectile made a hole in the target, but did not went through), projectile did not penetrate the target "dnp" (projectile bounced off leaving indentation in the target plate and p-stuck "ps" (projectile perforated target and stayed in the target protruding at the backside of the plate). For each penetration outcome, velocity and energy density were defined and compared to the skin penetration criteria. These data, combined with the damage on the steel plate, will clearly present energy levels of compressed air-based weapons and its possibilities.

\section{Results and Discussion}

Penetration test results are presented in the tables bellow. Velocity and energy density were determined for each projectile fired and penetration outcome is registered. Kinetic energy of the projectiles upon the impact was calculated according to:

$$
E_{k}=\frac{m v^{2}}{2}
$$

Where " $E_{k}$ " is kinetic energy of the projectile, " $m$ " is mass of the assembled projectile (penetrator + sabot) and " $v$ " is the velocity of the projectile. Velocity was recorder with high speed camera and calculated for the distance projectile has travelled. Velocity was measured only at the muzzle and kinetic energy and energy density were calculated also for muzzle velocity. Because target was placed only $500 \mathrm{~mm}$ in front of the barrel, there was no significant change in velocity prior to impact.

Table 1. presents penetration data for projectiles fired at $2 \mathrm{MPa}$ tank pressure. Both, blunt and sharp tip projectiles are fired at the target plate.

\begin{tabular}{|c|c|c|c|c|c|c|c|c|c|c|c|c|}
\hline \multirow{4}{*}{ 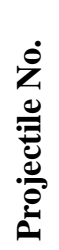 } & \multicolumn{12}{|c|}{ Chamber pressure $2 \mathrm{MPa}$} \\
\hline & \multicolumn{12}{|c|}{ Projectile diameter $5.5 \mathrm{~mm}$} \\
\hline & \multicolumn{6}{|c|}{ Sharp Projectile } & \multicolumn{6}{|c|}{ Blunt Projectile } \\
\hline & $\begin{array}{l}\text { Mass } \\
{[\mathrm{g}]}\end{array}$ & $\begin{array}{l}\text { Vel. } \\
{[\mathrm{m} / \mathrm{s}]}\end{array}$ & $\begin{array}{l}\text { Energy } \\
{[\mathrm{J}]}\end{array}$ & $\begin{array}{l}\text { Energy } \\
\text { density } \\
{\left[\mathrm{J} / \mathrm{cm}^{2}\right]}\end{array}$ & $\begin{array}{l}\text { Sectional } \\
\text { density } \\
{\left[\mathrm{g} / \mathrm{mm}^{2}\right]}\end{array}$ & $\begin{array}{l}\overrightarrow{0} \\
\stackrel{0}{0}\end{array}$ & $\begin{array}{l}\text { Mass } \\
{[\mathrm{g}]}\end{array}$ & $\begin{array}{l}\text { Vel. } \\
{[\mathrm{m} / \mathrm{s}]}\end{array}$ & $\begin{array}{l}\text { Energy } \\
{[\mathrm{J}]}\end{array}$ & $\begin{array}{l}\text { Energy } \\
\text { density } \\
{\left[\mathrm{J} / \mathrm{cm}^{2}\right]}\end{array}$ & $\begin{array}{l}\text { Sectional } \\
\text { density } \\
{\left[\mathrm{g} / \mathrm{mm}^{2}\right]}\end{array}$ & $\begin{array}{l}\dot{\overrightarrow{0}} \\
\stackrel{\tilde{D}}{2}\end{array}$ \\
\hline 1 & 12.30 & 95 & 55.39 & 233.13 & 0.518 & dnp & 12.56 & 105 & 69.24 & 291.42 & 0.529 & dnp \\
\hline 2 & 12.23 & 107 & 69.40 & 292.10 & 0.515 & $\mathrm{pp}$ & 12.49 & 104 & 67.55 & 284.30 & 0.526 & dnp \\
\hline 3 & 12.32 & 97 & 57.78 & 243.20 & 0.519 & dnp & 12.58 & 107 & 72.01 & 303.11 & 0.529 & dnp \\
\hline 4 & 12.34 & 102 & 63.82 & 268.60 & 0.519 & $\mathrm{pp}$ & 12.62 & 111 & 77.75 & 327.24 & 0.531 & $\mathrm{pp}$ \\
\hline 5 & 12.36 & 116 & 83.47 & 351.35 & 0.503 & $\mathrm{pp}$ & 12.61 & 114 & 81.94 & 344.89 & 0.531 & $\mathrm{pp}$ \\
\hline
\end{tabular}

Table 1. Penetration outcome for $2 \mathrm{MPa}$ chamber pressure 
Based on the penetration outcome, it can be seen that partial penetration is possible at velocities generally above 100 $\mathrm{m} / \mathrm{s}$. Projectiles that were able to perforate steel plate (made a small hole in the target) had higher energy than the ones which left only indentations on the target (dnp). Energy density was much higher than skin penetration limit which is ranging from $23.99 \mathrm{~J} / \mathrm{cm}^{2}$ up to $52.74 \mathrm{~J} / \mathrm{cm}^{2}$, depending on the place of impact on a human body [8].

\begin{tabular}{|c|c|c|c|c|c|c|c|c|c|c|c|c|}
\hline \multirow{4}{*}{ 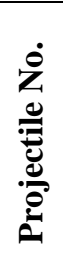 } & \multicolumn{12}{|c|}{ Chamber pressure $3 \mathrm{MPa}$} \\
\hline & \multicolumn{12}{|c|}{ Projectile diameter $5.5 \mathrm{~mm}$} \\
\hline & \multicolumn{6}{|c|}{ Sharp Projectile } & \multicolumn{6}{|c|}{ Blunt Projectile } \\
\hline & $\begin{array}{l}\text { Mass } \\
{[\mathrm{g}]}\end{array}$ & $\begin{array}{l}\text { Vel. } \\
{[\mathrm{m} / \mathrm{s}]}\end{array}$ & $\begin{array}{l}\text { Energy } \\
{[\mathrm{J}]}\end{array}$ & $\begin{array}{l}\text { Energy } \\
\text { density } \\
{\left[\mathrm{J} / \mathrm{cm}^{2}\right]}\end{array}$ & $\begin{array}{l}\text { Sectional } \\
\text { density } \\
{\left[\mathrm{g} / \mathrm{mm}^{2}\right]}\end{array}$ & $\begin{array}{l}\dot{0} \\
\stackrel{0}{0} \\
\text { D. }\end{array}$ & $\begin{array}{l}\text { Mass } \\
{[\mathrm{g}]}\end{array}$ & $\begin{array}{l}\text { Vel. } \\
{[\mathrm{m} / \mathrm{s}]}\end{array}$ & $\begin{array}{l}\text { Energy } \\
{[\mathrm{J}]}\end{array}$ & $\begin{array}{l}\text { Energy } \\
\text { density } \\
{\left[\mathrm{J} / \mathrm{cm}^{2}\right]}\end{array}$ & $\begin{array}{l}\text { Sectional } \\
\text { density } \\
{\left[\mathrm{g} / \mathrm{mm}^{2}\right]}\end{array}$ & $\begin{array}{l}\dot{0} \\
\stackrel{0}{0}\end{array}$ \\
\hline 1 & 12.66 & 135 & 115.36 & 485.57 & 0.533 & ps & 12.56 & 124 & 95.56 & 406.43 & 0.529 & ps \\
\hline 2 & 12.59 & 125 & 98.36 & 414.00 & 0.530 & ps & 12.64 & 110 & 76.47 & 321.87 & 0.532 & ps \\
\hline 3 & 12.68 & 118 & 88.28 & 371.57 & 0.534 & ps & 12.55 & 120 & 90.36 & 380.33 & 0.528 & ps \\
\hline 4 & 12.70 & 126 & 100.81 & 424.33 & 0.535 & ps & 12.66 & 108 & 73.83 & 310.77 & 0.533 & $\mathrm{ps}$ \\
\hline 5 & 12.72 & 120 & 91.58 & 384.48 & 0.535 & ps & 12.68 & 118 & 88.28 & 371.57 & 0.534 & $\mathrm{ps}$ \\
\hline
\end{tabular}

Table 2. Penetration outcome for $3 \mathrm{MPa}$ chamber pressure

All of the projectiles fired at 3 MPa chamber pressure, experienced p-stuck penetration outcome "ps", Table 2. Projectiles perforated steel plate and protruded on the other side staying in the target. Velocities at which impact has occurred were higher in some cases for more than $30 \%$ in comparison to $2 \mathrm{MPa}$ chamber pressure.

\begin{tabular}{|c|c|c|c|c|c|c|c|c|c|c|c|c|}
\hline \multirow{4}{*}{ 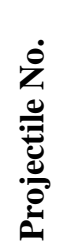 } & \multicolumn{12}{|c|}{ Chamber pressure $5 \mathrm{MPa}$} \\
\hline & \multicolumn{12}{|c|}{ Projectile diameter $5.5 \mathrm{~mm}$} \\
\hline & \multicolumn{6}{|c|}{ Sharp Projectile } & \multicolumn{6}{|c|}{ Blunt Projectile } \\
\hline & $\begin{array}{l}\text { Mass } \\
{[\mathrm{g}]}\end{array}$ & $\begin{array}{l}\text { Vel. } \\
{[\mathrm{m} / \mathrm{s}]}\end{array}$ & $\begin{array}{l}\text { Energy } \\
{[\mathrm{J}]}\end{array}$ & $\begin{array}{l}\text { Energy } \\
\text { density } \\
{\left[\mathrm{J} / \mathrm{cm}^{2}\right]}\end{array}$ & $\begin{array}{l}\text { Sectional } \\
\text { density } \\
{\left[\mathrm{g} / \mathrm{mm}^{2}\right]}\end{array}$ & $\begin{array}{l}\overrightarrow{0} \\
\overrightarrow{0} \\
\text { Q }\end{array}$ & $\begin{array}{l}\text { Mass } \\
{[\mathrm{g}]}\end{array}$ & $\begin{array}{l}\text { Vel. } \\
{[\mathrm{m} / \mathrm{s}]}\end{array}$ & $\begin{array}{l}\text { Energy } \\
{[\mathrm{J}]}\end{array}$ & $\begin{array}{l}\text { Energy } \\
\text { density } \\
{\left[\mathrm{J} / \mathrm{cm}^{2}\right]}\end{array}$ & $\begin{array}{l}\text { Sectional } \\
\text { density } \\
{\left[\mathrm{g} / \mathrm{mm}^{2}\right]}\end{array}$ & $\begin{array}{l}\dot{0} \\
\stackrel{0}{0} \\
\text { D. }\end{array}$ \\
\hline 1 & 12.13 & 148 & 132.85 & 559.16 & 0.511 & ps & 12.50 & 145 & 131.41 & 553.10 & 0.526 & $\mathrm{fp}$ \\
\hline 2 & 12.06 & 156 & 146.75 & 617.66 & 0.508 & ps & 12.58 & 150 & 141.53 & 595.69 & 0.529 & $\mathrm{fp}$ \\
\hline 3 & 12.15 & 146 & 129.49 & 545.05 & 0.511 & ps & 12.49 & 141 & 124.16 & 522.58 & 0.526 & $\mathrm{fp}$ \\
\hline 4 & 12.17 & 137 & 114.21 & 480.71 & 0.512 & ps & 12.61 & 135 & 114.91 & 483.66 & 0.531 & fp \\
\hline 5 & 12.19 & 145 & 128.15 & 539.38 & 0.513 & ps & 12.48 & 149 & 138.53 & 583.10 & 0.525 & $\mathrm{fp}$ \\
\hline
\end{tabular}

Table 3. Penetration outcome for $5 \mathrm{MPa}$ chamber pressure

At $5 \mathrm{MPa}$ chamber pressure, Table 3, only blunt projectiles were capable of full penetration of the steel plate while sharp projectiles expressed same behaviour as it was the case in $3 \mathrm{MPa}$ tests, that is the projectiles were stuck in the target. Sectional density was higher for the blunt projectiles because of their higher mass compared to the sharp ones. Since caliber of the projectile was identical for all shooting series, mass has the major influence on sectional density in this case.

In case of a $5 \mathrm{MPa}$ Chamber pressure conditions, piezo electric pressure sensor Kistler 6215 was added in front of the trigger valve in order to measure pressure inside the barrel after triggering. Recorded Pressure vs Time curves, Figure 3, resembles to those curves obtained in internal ballistics of firearms. Pressure drop is evident from these curves.
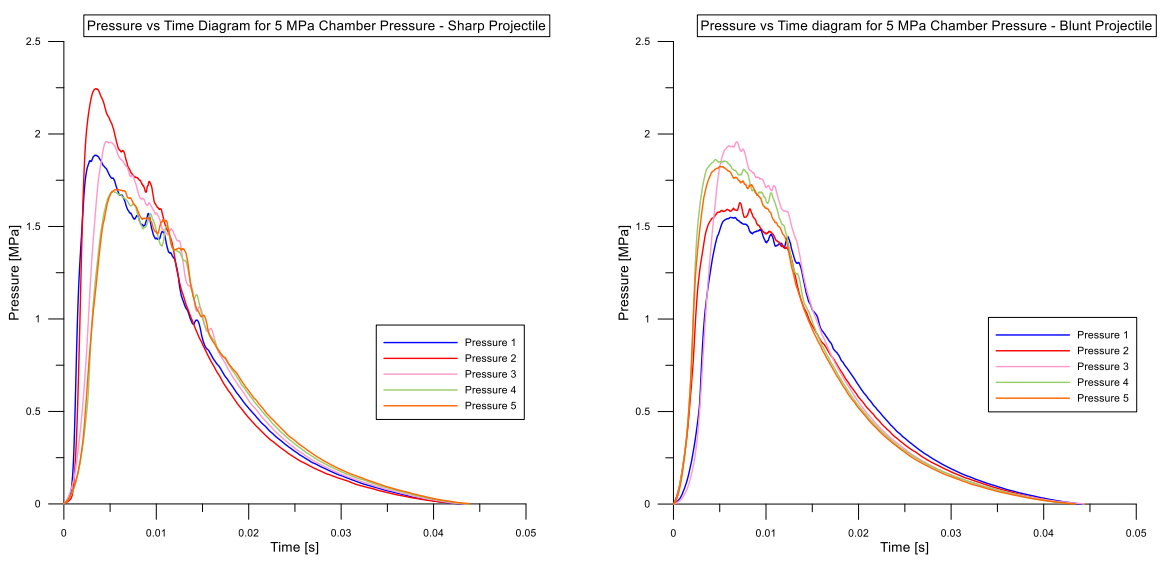

Fig. 3. Pressure vs Time diagrams for sharp and blunt projectiles fired at $5 \mathrm{MPa}$ 
Fig. 4. presents achieved penetration outcomes of the $2 \mathrm{~mm}$ steel plate. First image presents target damage in case of a projectile that bounced of the target leaving indentation in the target material (dnp). Second image is the result of the partial penetration (pp). Projectile did make a hole in the plate, but it was not capable of full penetration through the target body. In this case projectile also bounced of the target. The results of full penetration are presented in the third image (fp). Projectile went through the whole target continuing its motion after penetration. Fourth image presents effects of the projectile that has stuck in the target material (ps). This projectile was capable of penetrating the target making a hole size of a projectile caliber but it did not have enough kinetic energy to continue its motion further. Markings of the tool used to remove projectile from the target are visible on the fourth image from left to right (ps).
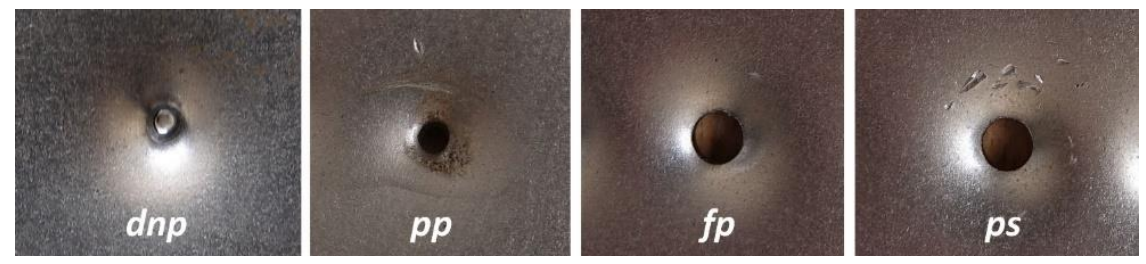

Fig. 4. Penetration outcomes

Table 4. shows energy levels and other parameters calculated for projectiles fired from Air Guns used in Paintball, Airsoft and for Performance riffles. Velocity and projectile mass were acquired from riffle/marker manufacturers and safety measurements provided from playground sites that use these kinds of guns according to regulations [1] [2] [3] [9].

\begin{tabular}{|ll|r|r|r|}
\hline \multicolumn{2}{|c|}{ Projectile parameters } & \multicolumn{1}{c|}{$\begin{array}{c}\text { Paintball } \\
\text { Marker }\end{array}$} & \multicolumn{1}{c|}{$\begin{array}{c}\text { Airsoft } \\
\text { Marker }\end{array}$} & \multicolumn{1}{c|}{$\begin{array}{c}\text { Air } \\
\text { Riffle }\end{array}$} \\
\hline Mass & {$[\mathrm{g}]$} & 3.0 & 0.4 & 0.490 \\
\hline Diameter & {$[\mathrm{mm}]$} & 17.270 & 6.000 & 4.500 \\
\hline Projected Area & {$\left[\mathrm{cm}^{2}\right]$} & 2.342 & 0.283 & 0.159 \\
\hline Velocity & {$[\mathrm{m} / \mathrm{s}]$} & 91.0 & 150.0 & 470.0 \\
\hline Energy & {$[\mathrm{J}]$} & 12.422 & 4.500 & 54.121 \\
\hline Sectional density & {$\left[\mathrm{g} / \mathrm{mm}^{2}\right]$} & 0.013 & 0.014 & 0.031 \\
\hline Energy density & {$\left[\mathrm{J} / \mathrm{cm}^{2}\right]$} & 5.303 & 15.915 & 340.288 \\
\hline
\end{tabular}

Table 4. Parameters of projectiles used in various Air Guns

Energy density at which $50 \%$ risk of skin penetration is possible is ranging between $23.99 \mathrm{~J} / \mathrm{cm}^{2}$ up to $52.74 \mathrm{~J} / \mathrm{cm}^{2}$, depending on the place where human body was hit [8]. According to velocity levels regulated by the safety measures, energy density achieved from Paintball and Airsoft markers is not sufficient for skin penetration. Energy and Sectional density are too low to produce any significant damage to the skin, bones or muscles. However, it is still possible to cause serious eye injury with these types of Air Guns [10] [11]. When performance riffle characteristics are observed, it is evident that skin penetration energy density limit is exceeded more than 10 times. Even though energy density of the projectiles fired from custom made air gun could be compared with performance rifles, sectional density was significantly lower in performance rifle projectiles. Gun used in this test was of much higher power than markers/riffles used in entertainment.

\section{Conclusion}

Air guns used in entertainment generally have low velocities and low operational pressure. Excluding performance rifles which can achieve velocity up to couple of hundred meters per second, other entertainment guns should not be able to inflict serious injuries to bones, skin, muscles etc.

Experiment described in this paper is not solely intended to compare air guns and its injury capabilities. Main premise was to present energy levels of compressed air in projectile propelling and its possibilities in penetration of the steel target. Energies achieved in custom made air gun clearly describes possibilities of compressed air by visual interpretation of the plate perforations using steel projectiles.

Even though these levels of compression are not present in the entertainment guns/markers, it is possible to achieve them by some sort of marker modification. It is important to emphasize that these modifications are against the regulations. Modified markers must not be used in playgrounds or any sort of activity where someone could be injured. Custom made Air gun used in these experiments was operated by the trained personnel in safe laboratory conditions with protective plates against ricochet. Safety measures are also taken in case of air tank burst.

Further research on the subject of penetration abilities of the projectiles should be performed on organic targets such as porcine meat with skin and bones. These results will provide possible comparison of energies needed for target penetration similar to a human body. 


\section{References}

[1] http://lvlupsports.com, (2021). LVL UP Sports, Sports Safety Rules, Accessed on: 20-07-21.

[2] http://paintball-command.com, (2021). Paintball Command, Airsoft Equipment Rules, Accessed on: 20-07-21.

[3] http://www.gamo.co.za, (2021). Gamo Precision Air Guns, Gamo G magnum, Accessed on: 07-07-21.

[4] http://www.floridaairsoft.com, (2021). FA, Airsoft and Paintball Kinetic Energies, Accessed on: 08-08-21.

[5] Ficek, M.; Malanik, Z.; Mikulicova, M. \& Gracla, M., (2019). Influence of the Shooting Distance on the Depth of Penetration of the Bullet into the Replacement Material for Air Gun Weapons, Proceedings of the 30th DAAAM International Symposium, pp.0663-0672, B. Katalinic (Ed.), Published by DAAAM International, ISBN 978-3902734-22-8, ISSN 1726-9679, Vienna, Austria DOI: 10.2507/30th.daaam.proceedings.091.

[6] Ficek, M.; Juricek, L.; Gracla, M.; Malanik, Z. \& Mikulicova, M. (2020). Determination of Wounding Potential of Guns Known from Childhood - Blowpipe and Slingshot, Chapter 19 in DAAAM International Scientific Book 2020, pp.227-236, B. Katalinic (Ed.), Published by DAAAM International, ISBN 978-3-902734-27-3, ISSN 1726- 9687, Vienna, Austria DOI: 10.2507/daaam.scibook.2020.19.

[7] Dumencic, B.; Rajc, J.; Pavokovic, D. \& Damjanovic, T. (2020). "Fatal injury by air gun: a case report," Egyptian Journal of Forensic Sciences, Vol. 10, No. 7., DOI:https://doi.org/10.1186/s41935-020-00182-7.

[8] Bir, C. A., Stewart, S. J. \& Wilhelm, M. (2005). "Skin Penetration Assessment of Less Lethal Kinetic Energy Munitions", Journal of Forensic Sciences, Vol. 50, No. 6, pp. 1426-1429., Paper ID JFS2004551.

[9] http://www.liveabout.com, (2018). LiveAbout, Choosing the Right Paintball Caliber, Accessed on: 23-08-21.

[10] Farr, A. K. \& Fekrat, S. (1998). "Eye injuries associated with paintball guns", The International Journal of Clinical Ophthalmology and Visual Sciences, Vol. 22, pp. 169-173., DOI: 10.1023/a:1006216125152.

[11] Kennedy, E. A., P Ng, T. \& Duma, S. (2006). "Evaluating eye injury risk of Airsoft pellet guns by parametric risk functions", Biomedical Sciences Instrumentation, Vol. 42, pp. 7-12., PMID: 16817577. 